\title{
PENGEMBANGAN MEDIA PEMBELAJARAN FISIKA MENGGUNAKAN SWISH MAX4 MEMAHAMI KONSEP MOMENTUM IMPULS DAN TUMBUKAN DI SMA
}

\author{
Febri Yanti ${ }^{1}$, Astalini ${ }^{2}$, dan Wawan Kurniawan ${ }^{3}$ \\ ${ }^{1}$ Mahasiswa S1 Program Studi Pendidikan Fisika FKIP Universitas Jambi \\ ${ }^{2,3}$ Dosen Program Studi Pendidikan Fisika FKIP Universitas Jambi \\ Email: febriyanti703@yahoo.co.id
}

\section{Info Artikel}

Diterima:

13 Februari 2018

Disetujui:

25 Januari 2019

Dipublikasikan:

30 Juni 2019

\begin{abstract}
Abstrak
Penelitian bertujuan untuk mengembangkan media pembelajaran fisika menggunakan SWiSH Max4 materi momentum impuls tumbukan kelas X MIPA SMA yang valid dan layak. Jenis penelitian merupakan penelitian dan pengembangan. Langkah-langkah dalam pengembangan Luther, meliputi: Concept, Design, Material Collecting, Assembly, Testing. Subjek uji coba penelitian adalah siswa kelas XMIPA4 SMA 11 KotaJambi. Instrumen pengumpulan data menggunakan lembar validasi materi, media dan angket persepsi siswa. Data dianalisis secara deskriptif. Media dikembangkan memiliki format flash, movie dan exe. Materi disajikan disertai teks, gambar, video dan animasi. Hasil validasi media dan materi dinyatakan layak oleh validator. Skor hasil analisis dari persepsi siswa untuk aspek pendidikan, mencapai skor 135 (sangat baik), aspek tampilan program 138,8 (sangat baik), dan aspek kualitas teknik 132,3 (sangat baik). Media pembelajaran fisika menggunakan SWiSH Max4 valid dan layak digunakan.
\end{abstract}

Kata kunci: SwiSH Max4, flash, media pembelajaran fisika

\begin{abstract}
:
The research aims to develop physics learning media using SWiSH Max4 a valid and viable class of collision impulse momentum material X MIPA SMA. This type of research was research and development. The steps in the development of Luther include: concept, design, material collecting, assembly, and testing. The subject of the research trials was the students XMIPA4 SMA 11 Jambi City. Data collection instruments using material validation sheets, media and student perception quisionare. Data were analyzed descriptively. The Media developed has flash, movie and EXE formats. The material was presented with text, images, video and animation. Media and material validation results are declared feasible by the validator. Score analysis of the students' perceptions for educational aspects, achieving a score of 135 (very good), the display aspect of the program 138.8 (very good), and the aspect of the technical quality of 132.3 (very good). Physics learning Media using SWiSH Max4 is valid and well worth use.
\end{abstract}

Keywords: SwiSH Max4, flash, physics learning media 


\section{Pendahuluan}

Undang-Undang No 20 tahun 2003 tentang Sistem Pendidikan Nasional pasal 1 ayat (1) Sistem pendidikan nasional adalah keseluruhan komponen pendidikan yang saling terkait secara terpadu untuk mencapai tujuan pendidikan nasional. Diperlukan sistem pendidikan yang mencetak siswa yang mandiri, dan berwawasan luas, maka dari itu untuk melaksanakan hal tersebut membutuhkan kurikulum yang mampu mencapai tujuan pendidikan tertentu. Berkaitan dengan itu kurikulum 2013 merupakan penyempurnaan dari Kurikulum Tingkat Satuan Pendidikan (KTSP) yang saat ini telah diterapkan di Indonesia. Kurikulum 2013 diharapkan mampu memecahkan permasalah dalam dunia pendidikan dengan menciptakan siswa yang memiliki aspek kognitif, afektif, dan psikomotor. Namun dengan adanya perubahan kurikulum 2013 ini yang proses pembelajarannya berpusat pada siswa, dimana siswa harus berfikir kritis untuk menyelesaikan masalah dan memperluas materi. Sehingga tidak hanya di kelas saja siswa dapat memperoleh pengetahuan yang di dapat dari guru, namun di luar kelas dan dari berbagai sumber.

Berdasarkan hasil observasi yang dilakukan penulis selama Praktik Pengenalan Lapangan (PPL) di SMA Negeri 11 Kota Jambi, ditemui fakta siswa masih kurang memahami materi fisika karena guru belum menjalankan proses pembelajaran sesuai prosedur kurikulum 2013. Hal ini disebabkan oleh materi dan kompetensi yang menjadi tuntutan kurikulum 2013 cukup banyak sedangkan alokasi waktu tidak cukup untuk membahas semua materi tersebut. Selain itu keterbatasan kemampuan dan kreatifitas dari guru itu sendiri dalam mengembangkan media yang bisa digunakan oleh siswa untuk belajar mandiri. Untuk itu siswa memenuhi tuntutan materi tersebut, siswa memanfaatkan waktu di luar jam pelajaran, baik itu mengikuti tambahan pelajaran/les maupun belajar mandiri di rumah.

Sebagian besar materi fisika berupa konsep. Konsep adalah suatu gagasan abstrak yang digeneralisasi dari contoh-contoh khusus (Slavin, 2008:215). Untuk memahami konsepkonsep fisika diperlukan adanya media pembelajaran yang dibutuhkan pengajar. Media pembelajaran adalah segala sesuatu yang dapat digunakan untuk menyalurkan pesan (bahan pembelajaran) sehingga dapat merangsang perhatian, minat, pikiran dan perasaan siswa dalam kegiatan belajar untuk mencapai tujuan pendidikan. Berbagai macam media yang dapat digunakan, dari yang diproyeksikan dan yang tidak diproyeksikaan. Salah satu contoh media yang diproyeksikan adalah media berbasis animasi. Menurut Vaughan dalam Binanto (2010:219) animasi merupakan perubahan visual sepanjang waaktu yang memberi kekuatan besar pada proyek multimedia dan halaman web yang dibuat.

Dengan menggunakan media, proses pembelajaran dapat dilakukan dan tanpa dibatasi oleh waktu pembelajaran di sekolah. Media animasi dapat dibuat dengan menggunakan berbagai macam software, salah satunya yaitu SWiSH Max4. SWiSH Max4 merupakan pengembangan dari Program Swish v.2, yang kini telah memiliki 230 bulit-in efek seperti efek Explode, Vortex, 3D Spin, Snake dan banyak lainnya. Seperti halnya Swish, SwishMax juga memilki alat bantu untuk membuat garis, kotak, elips, kurva bazier, gerak animasi, sprite, tombol roll over dan lainnya. Format dasar SWiSH Max4 adalah swi, namun dapat juga diekspor kedalam file flash (swf), movie (avi) ataupun execute (exe) program yang dapat dijalankan sendiri. Sehingga animasi Swishmax dapat diletakkan langsung di web, ataupun diikutkan dalam presentasi Microsoft Powerpint dan Microsoft Word. Bentuk file $s w f$ dapat dimainkan melalui adobe flash player, baik di komputer maupun di beberapa android sehingga dapat digunakan siswa untuk menunjang proses pembelajaran mandiri (Agus 2005:2).

Penelitian ini bertujuan untuk mengembangkan media pembelajaran fisika menggunakan Swish Max pada materi momentum impuls dan tumbukan di SMA. dan mengetahui persepsi siswa terhadap media pembelajaran fisika ini. Manfaat dari penelitian ini adalah membantu siswa dalam memperdalam pembelajaran fisika, karena siswa dapat melakukan pembelajaran fisika dimana saja dan kapan saja dan dapat digunakan sebagai media pembelajaran sehingga dapat belajar mandiri. 


\section{Metode Penelitian}

Jenis Penelitian

Jenis penelitian ini adalah penelitian

dan pengembangan (Research and Development). Model pengembangan yang digunakan adalah model Luther dalam Ariesto (2003) pengembangan media pembelajaran dilakukan dalam 6 tahap yaitu: concept, design, material collecting, assembly, testing, dan distribution. Namun dalam penelitian ini hanya dilakukan sampai tahap testing (pengujian), hal ini dikarenakan pada penelitian ini peneliti hanya bermaksud untuk mengembangkan produk, belum sampai pada tahap distribusi dan penjualan produk yang dihasilkan.

\section{Waktu dan Tempat Penelitian}

Penelitian dilaksanakan di SMAN 11

Kota Jambi pada tanggal 14 Desember 2017.

Prosedur Pengembangan

Prosedur pengembangan media pembelajaran fisika menggunakan Swish Max4 pada materi momentum impuls dan tumbukan ini hanya dibatasi pada tahap testing (uji coba).

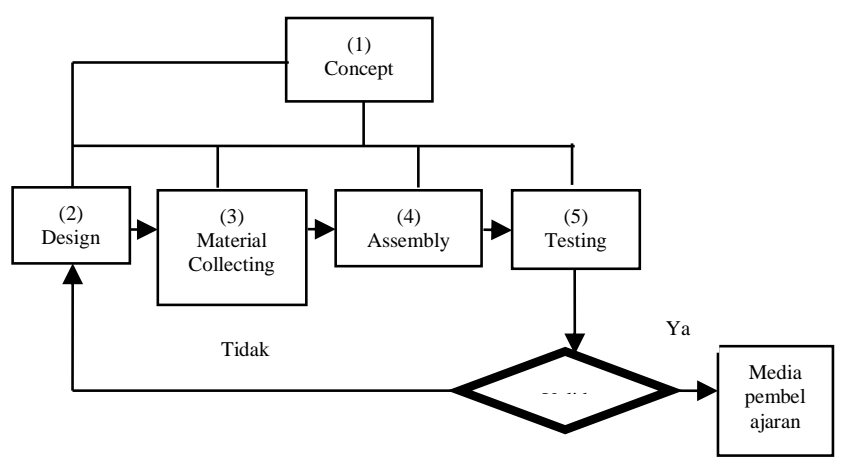

Gambar 1. Model Pengembangan Multimedia Luther (Ariesto H.S, 2003)

1. Concept (pembuatan konsep)

Tahapan yang dilakukan dalam tahap konsep meliputi menentukan tujuan media pembelajaran, menentukan konsep materi pembelajaran dan menentukan konsep isi media pembelajaran. Konsep materi pembelajaran mengacu pada silabus kurikulum 2013 dengan mengambil materi momentum impuls dan tumbukan serta menganalisa kebutuhan media yang digunakan melalui studi literatur.

\section{Design (Perancangan)}

Tahap ini dimulai dengan menyusun isi program, menentukan urutan penyajian dan menyusun alur pembelajaran yang berupa flowchart. Hal ini ditujukan agar pembuatan media pembelajaran lebih terarah. Langkahlangkah perancangannya meliputi:

a. Penulisan naskah materi yang akan dibuat sebagai media pembelajaran.

b. Pembuatan Storyboard di lampirkan

c. Menyusun alur pembelajaran yang berupa flowchart media pembelajaran momentum dan impuls

d. Perancangan screen media

e. Menyusun garis besar isi dalam media secara garis besar isi dalam program media

\section{Material Collecting (Pengumpulan bahan)}

Tahap ini merupakan tahap lanjutan dari tahap perancangan. Adapun urutan dalam proses pengumpulan bahan sebagai berikut:

a. Pengumpulan bahan-bahan yang diperlukan untuk media seperti animasi, musik, gambar.

b. Pemrograman media dibuat dengan menggunakan program Swish Max4. Tahap ini digunakan sebagai bahan penjabaran dari garis besar isi program media yang telah disusun.

4. Assembly (Tahap pembuatan media yang dihasilkan)

tahap dimana seluruh objek media dibuat. Langkah-langkah yang dilakukan dalam pembuatan media adalah:

a. Mengintegrasikan semua materi yang telah dibuat kedalam screen sesuai dengan storyboard yang telah dibuat.

b. Mentransfer semua komponen yang telah dibuat kedalam screen dengan menggunakan program SwishMax4.

c. Setelah proses pemrograman selesai dilanjutkan dengan proses penyuntingan dan pengemasan media pembelajaran dalam bentuk flash.

\section{Testing (Tahap uji coba dan evaluasi)}

Setelah tahap pembuatan dan seluruh data telah dimasukan, maka dilakukan pengujian untuk memastikan apakah media yang dibuat mencapai tujuan pembuatannya. yang kemudian divalidasi oleh ahli media dan 
ahli materi dilanjutkan dengan revisi sesuai dengan saran dan komentar yang diberikan sebelum diuji cobakan kepada siswa yang kemudian dilakukan evaluasi. Program yang telah divalidasikan kemudian diuji cobakan pada beberapa siswa sebagai subyek penelitian. Siswa yang terlibat adalah siswa yang belum memperoleh materi yang terdapat dalam media pembelajaran tersebut, akan tetapi sudah mengetahui prasyarat yang diperlukan. Proses uji coba dilakukan hanya sekali dan selanjutnya akan dilakukan revisi jika lembar evaluasi media pembelajaran tidak memenuhi kriteria interpretasi.

\section{Subjek Uji Coba}

Untuk menguji persepsi siswa terhadap media pembelajaran fisika menggunakan Swish Max maka peneliti melakukan penelitian di SMA 11 Kota Jambi Kelas X MIPA 4. Uji persepsi siswa ditujukan untuk mengetahui kelayakan media pembelajaran fisika menggunakan Swish Max yang dibuat. Disini peneliti melibatkan sebanyak 30 siswa untuk menguji persepsi siswa.

\section{Jenis Data}

Jenis data yang digunakan pada penelitian pengembangan ini bersifat kualitatif dan kuantitatif. Data kualitatif yang diambil adalah saran dari tim validasi ahli, sedangkan data kuantitatif yang diambil adalah angket persepsi siswa. Data yang diperoleh dari hasil pengembangan produk ini digunakan sebagai dasar dalam menetapkan kelayakan media pembelajaran fisika menggunakan Swish Max

Instrumen Pengumpulan Data

1. Validasi media dan

materi

Lembar validasi ini digunakan untuk mengukur kevalidan media pembelajaran yang akan dikembangkan, agar layak untuk digunakan maka ditunjuk ahli materi dan ahli media untuk mengoreksi media pembelajaran yang dikembangkan. a. Validasi media

Tabel 1. Kisi-kisi validasi ahli media

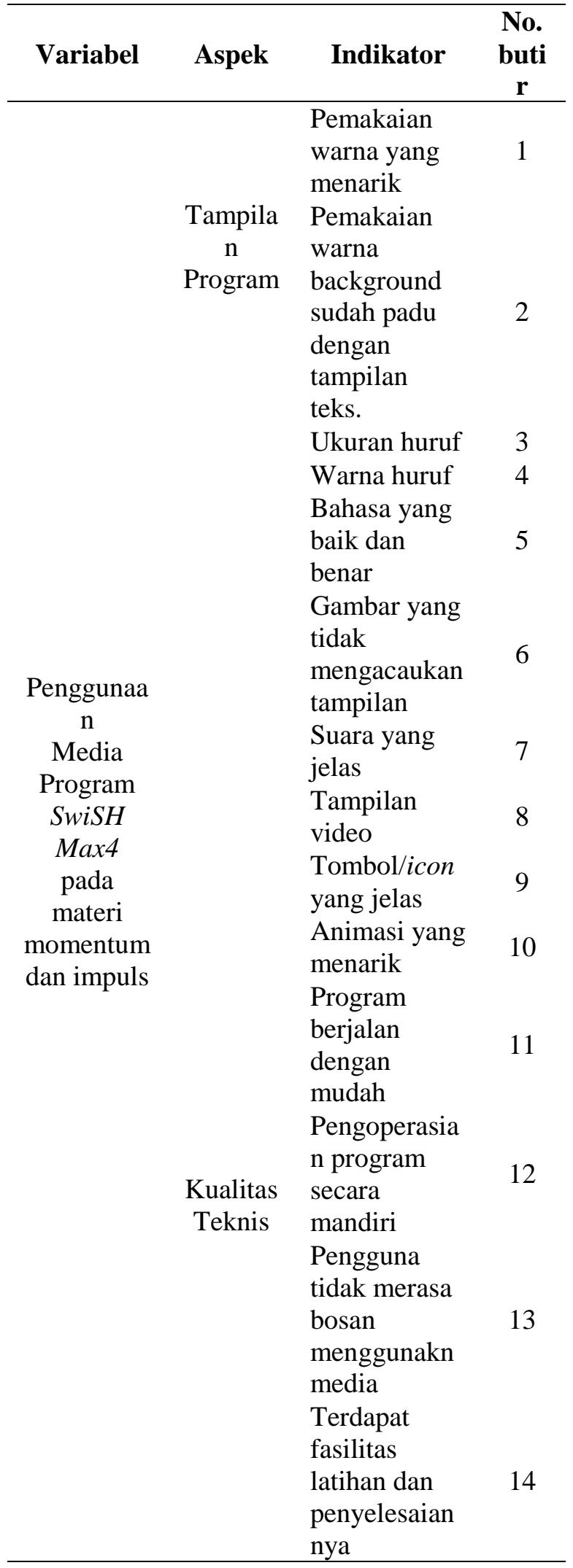


Pada validasi tahap I validator menyarankan beberapa hal sebagai berikut:

1. Memperbaiki warna pada tulisan.

2. Memperbaiki background.

3. Menambahkan keterangan/sumber refrensi digambar.

4. Menambah tombol ikon back ditambahkan ke scene awal.

Pada validasi tahap II validator ahli media sudah menceklis semua pertanyaan dalam angket, sehingga media layak untuk digunakan.

b. Validasi materi Tabel 2. Kisi-kisi validasi ahli materi

\begin{tabular}{|c|c|c|c|}
\hline Variabel & Aspek & Indikator & $\begin{array}{c}\text { No. } \\
\text { Buti } \\
\text { r }\end{array}$ \\
\hline \multirow{12}{*}{$\begin{array}{c}\text { Penggunaa } \\
\text { n } \\
\text { Media } \\
\text { Program } \\
\text { SwiSH } \\
\text { Max4 } \\
\text { pada } \\
\text { materi } \\
\text { momentum } \\
\text { dan impuls }\end{array}$} & \multirow{6}{*}{$\begin{array}{l}\text { Tampila } \\
\text { n Materi }\end{array}$} & $\begin{array}{l}\text { Kesesuaian } \\
\text { materi dengan } \\
\text { silabus } \\
\text { kurikulum }\end{array}$ & 1 \\
\hline & & $\begin{array}{l}\text { Menjelaskan } \\
\text { konsep materi }\end{array}$ & 2 \\
\hline & & $\begin{array}{l}\text { Pemahaman } \\
\text { materi }\end{array}$ & 3 \\
\hline & & $\begin{array}{l}\text { Bahasa yang } \\
\text { mudah } \\
\text { dimengerti }\end{array}$ & 4 \\
\hline & & $\begin{array}{l}\text { Relevan dengan } \\
\text { materi yang ada }\end{array}$ & 5 \\
\hline & & $\begin{array}{l}\text { Kemungkinan } \\
\text { siswa belajar } \\
\text { mandiri }\end{array}$ & 6 \\
\hline & \multirow{3}{*}{$\begin{array}{c}\text { Tampila } \\
\mathrm{n} \\
\text { animasi }\end{array}$} & $\begin{array}{l}\text { Kecocokan } \\
\text { simulasi dengan } \\
\text { materi }\end{array}$ & 7 \\
\hline & & $\begin{array}{l}\text { Tampilan } \\
\text { simulasi yang } \\
\text { menarik }\end{array}$ & 8 \\
\hline & & $\begin{array}{l}\text { Simulasi } \\
\text { mendorong } \\
\text { motivasi dalam } \\
\text { menjawab soal }\end{array}$ & 9 \\
\hline & \multirow{3}{*}{$\begin{array}{l}\text { Tampila } \\
\text { n latihan } \\
\text { soal }\end{array}$} & $\begin{array}{l}\text { Soal latihan } \\
\text { yang bervariasi }\end{array}$ & 10 \\
\hline & & $\begin{array}{l}\text { Mempermudah } \\
\text { menganalisis } \\
\text { soal }\end{array}$ & 11 \\
\hline & & $\begin{array}{l}\text { Kecocokan soal } \\
\text { dengan latihan } \\
\text { materi }\end{array}$ & 12 \\
\hline
\end{tabular}

Pada validasi tahap I validator langsung

menceklis semua pertanyaan dalam angket tanpa revisi. Ini berarti, media dinyatakan layak untuk digunakan.

2. Angket persepsi siswa

Tabel 3. Kisi-kisi angket persepsi siswa

\begin{tabular}{|c|c|c|}
\hline Kriteria & Indikator & $\begin{array}{l}\text { Item } \\
\text { soal }\end{array}$ \\
\hline \multirow{6}{*}{ Pendidikan } & $\begin{array}{l}\text { Menyajikan topik yang } \\
\text { jelas }\end{array}$ & 1 \\
\hline & $\begin{array}{l}\text { Relevan dengan materi } \\
\text { yang dipelajari }\end{array}$ & 2 \\
\hline & Isi materi mempunyai & 3 \\
\hline & konsep yang benar & \\
\hline & $\begin{array}{l}\text { Media pembelajaran } \\
\text { fisika memungkinkan } \\
\text { siswa belajar mandiri }\end{array}$ & 4 \\
\hline & $\begin{array}{l}\text { Pemakaian warna } \\
\text { membantu pemahaman } \\
\text { konsep }\end{array}$ & 5 \\
\hline \multirow{5}{*}{$\begin{array}{l}\text { Tampilan } \\
\text { program }\end{array}$} & $\begin{array}{l}\text { Program menggunakan } \\
\text { karakter huruf yang jelas }\end{array}$ & 6 \\
\hline & $\begin{array}{l}\text { Pewarnaan tidak } \\
\text { mengacaukan tampilan } \\
\text { layar }\end{array}$ & 7 \\
\hline & $\begin{array}{l}\text { Animasi membantu } \\
\text { mengingat } \\
\text { materi/informasi yang } \\
\text { dipelajari }\end{array}$ & 8 \\
\hline & $\begin{array}{l}\text { Animasi terlihat jelas dan } \\
\text { mudah dipahami }\end{array}$ & 9 \\
\hline & $\begin{array}{l}\text { Program dapat dimulai } \\
\text { dengan mudah }\end{array}$ & 10 \\
\hline \multirow{3}{*}{$\begin{array}{l}\text { Kualitas } \\
\text { teknis }\end{array}$} & $\begin{array}{l}\text { Anda tidak merasa bosan } \\
\text { belajar dengan media } \\
\text { pembelajaran ini }\end{array}$ & 11 \\
\hline & $\begin{array}{l}\text { Anda dapat mengulangi } \\
\text { pada bagian pelajaran } \\
\text { yang diinginkan }\end{array}$ & 12 \\
\hline & $\begin{array}{l}\text { Anda termotivasi belajar } \\
\text { fisika setelah } \\
\text { menggunakan media } \\
\text { pembelajaran ini }\end{array}$ & 13 \\
\hline
\end{tabular}

Berdasarkan hasil validasi media dan ahli materi, media pembelajaran yang selesai di kembangkan kemudian dilakukana uji cobakan kepada responden menggunakan angket persepsi siswa. Persepsi tersebut meliputi aspek pendidikan, aspek tampilan program, 
dan aspek kualitas teknis.

Analisis Reliabilitas

Cara yang digunakan untuk pengujian reliabilitas salah satunya dengan menggunakan teknik alfa cronbach. Menurut Arikunto (2015), rumus koefisien reliabilitas alfa cronbach yaitu:

$$
r_{11}=\left(\frac{n}{n-1}\right)\left(1-\frac{\Sigma \sigma_{i}^{2}}{\sigma_{t}^{2}}\right)
$$

Dengan:

$$
\sigma_{t}^{2}=\frac{\Sigma X^{2}-\frac{(\Sigma X)^{2}}{N}}{N}
$$

Keterangan:

$r_{11} \quad=$ indeks korelasi (harga reliabilitas)

$n \quad=$ banyaknya butir soal

$\Sigma \sigma_{i}^{2} \quad=$ jumlah varians butir.

$\sigma_{t}^{2} \quad=$ varians total.

$N \quad=$ banyak peserta yang mengisi angket

Tabel 4. Interpretasi Nilai $r$

\begin{tabular}{rc}
\hline Besarnya nilai $\mathrm{r}$ & Interpretasi \\
\hline $0,81<\mathrm{r} \leq 1,00$ & Sangat tinggi \\
$0,61<\mathrm{r} \leq 0,80$ & Tinggi \\
$0,41<\mathrm{r} \leq 0,60$ & Cukup Tinggi \\
$0,21<\mathrm{r} \leq 0,40$ & Rendah \\
$0,00<\mathrm{r} \leq 0,20$ & Sangat rendah \\
\hline \multirow{3}{*}{2015} & Sumber: Arikunto,
\end{tabular}

Teknik Analisis Data

1. Analisis data kualitatif

Data kualitatif yang berupa saran dari dosen 1.pembimbing disajikan secara deskriptif kualitatif (reduksi data, penyajian data dan verifikasi). Sedangkan pada saat melakukan penelitian dilakukann dengan cara dokumentasi (berupa foto).

2. Analisis data kuantitatif

Analisis data kuantitatif dilakukan secara statistik deskriptif (mean, median, modus, standar

deviasi maksimum dan minimum). Cara mecari data mean, median, modus, standar deviasi maksimum dan minimum dengan menggunakan bantuan software Microsoft excel 2007. Adapun skala yang digunakan pada angket persepsi ini yaitu angket dengan skala empat.

Hasil skor responden dinyatakan dengan

Kriteria interpretasi skor untuk skala Likert dengan skala empat dirumuskan sebagai berikut:

Tabel 5. Kriteria Interpretasi Skor

\begin{tabular}{cc}
\hline Rentang Skor & Kriteria \\
\hline $\mathrm{Mi}+1,8 \mathrm{SDi} \leq \bar{M} \leq \mathrm{Mi}+3,0 \mathrm{SDi}$ & Amat baik \\
$\mathrm{Mi}+0,6 \mathrm{SDi} \leq \bar{M}<\mathrm{Mi}+1,8 \mathrm{SDi}$ & Baik \\
$\mathrm{Mi}-0,6 \mathrm{SDi} \leq \bar{M}<\mathrm{Mi}+0,6 \mathrm{SDi}$ & Cukup baik \\
$\mathrm{Mi}-1,8 \mathrm{SDi} \leq \bar{M}<\mathrm{Mi}-0,6 \mathrm{SDi}$ & Cukup \\
$\mathrm{Mi}-3 \mathrm{SDi} \leq \bar{M}<\mathrm{Mi}-1,8 \mathrm{SDi}$ & Kurang \\
\hline \multicolumn{2}{c}{ Sumber: Direktorat Pembinaan SMA, 2010 }
\end{tabular}

Tabel di atas diturunkan dari kurva normal terhadap skala Likert

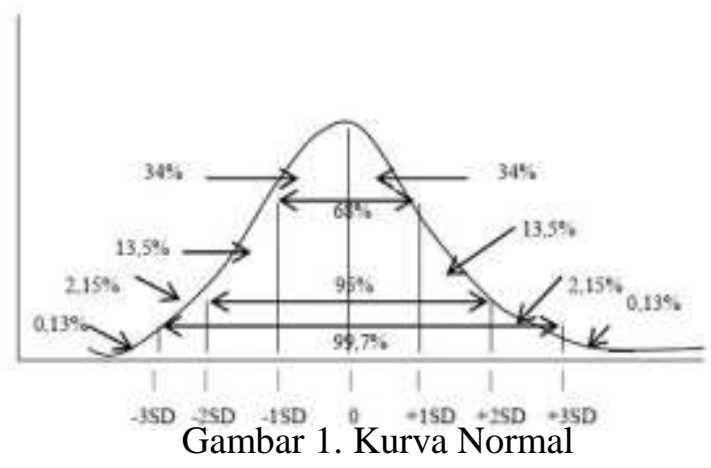

Sumber: Direktorat Pembinaan SMA, 2010

dengan:

$\mathrm{Mi} \quad=1 / 2($ Skor Maks + Skor Min $)$

SDi $=1 / 6$ (Skor Maks - Skor Min)

\section{Hasil dan Pembahasan}

Hasil pengembangan dari penelitian ini adalah berupa media pembelajaran fisika berbentuk flash pada materi momentum impuls dan tumbukan yang dibuat dengan menggunakan software SWiSH Max 4. Pengembangan media pembelajaran momentum impuls dan tumbukan pada penelitian ini dilakukan beberapa tahapan, (1) Concept yaitu menentukan tujuan media pembelajaran, menentukan konsep materi pembelajaran dan menentukan konsep isi 
media pembelajaran. (2) Design yaitu tahap perancangan materi, pembuatan flowchart dan pembuatan storyboard. (3) Material collecting yaitu tahap pengumpulan bahan yang sesuai dengan kebutuhan yang dikerjakan. (4) Assembly yaitu tahap menterjemahkan rancangan desain yang sebelumnya dibuat ke tampilan sebenarnya. (5) Testing yaitu tahap membuat rancangan menjadi produk yang valid produk berupa media pembelajaran fisika berbentuk flash.

\section{Hasil validasi produk}

Sebelum diuji coba, media pembelajaran sebelumnya harus melewati uji validitas agar media yang dihasilkan sesuai. Uji coba ini dilakukan dengan menunjuk dua orang ahli yang meliputi ahli materi dan ahli media Dari hasil validasi maka dilakukan perbaikanperbaikan sebagai berikut.

Sebelum Perbaikan Setelah Perbaikan
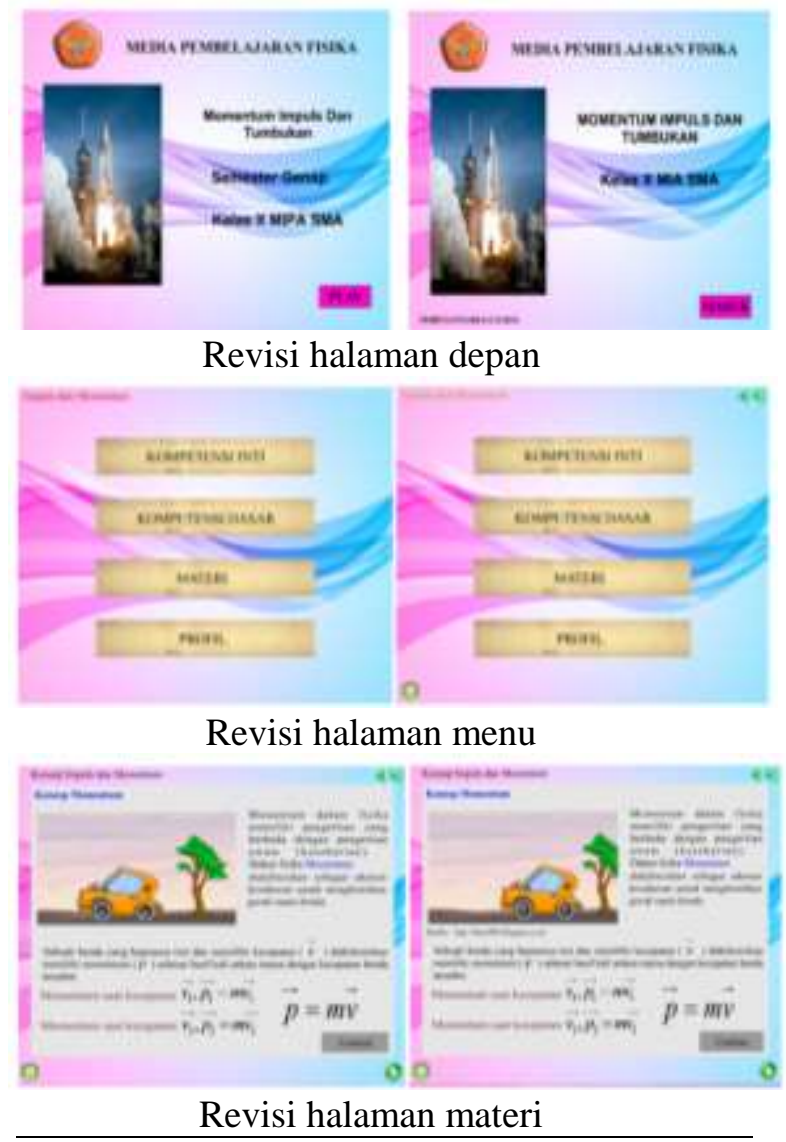

Tabel 6. Hasil perbaikan setelah revisi

\section{Hasil persepsi siswa}

Uji coba dilakukan dengan menyebarkan angket kepada siswa. Angket ini terdiri dari tiga indikator yang akan diukur yaitu, pendidikan, tampilan program dan kualitas teknis. Uji yang pertama adalah uji reabilitas angket dengan menggunakan koefisien korelasi dari persamaan Alpha Cronbach's dan mendapatkan nilai reabilitas sebesar 0,7667, angka ini menunjukkan bahwa angket yang digunakan termasuk kedalam kategori tinggi.

Uji coba kedua adalah untuk mengukur persepsi siswa terhadap kelayakan media pembelajaran menggunakan Swish Max .yang telah dikembangkan, dari hasil persepsi siswa didapatkan hasil aspek pendidikan mencapai skor 135 (amat baik), aspek tampilan program mencapai skor 138,8 (amat baik), dan aspek kualitas teknis mencapai skor 132,3 (amat baik).

Berdasarkan angket prestasi siswa di dapatkan skor angket sebagai berikut:

Tabel 7. Hasil persepsi siswa

\begin{tabular}{ccc}
\hline Aspek Penilaian & Skor & Kriteria \\
\hline Pendidikan & 135 & Amat baik \\
Tampilan program & 138,8 & Amat baik \\
Kualitas teknis & 132,3 & Amat baik \\
$\begin{array}{c}\text { Rata-rata aspek } \\
\text { keseluruhan }\end{array}$ & 135,8 & Amat baik \\
\hline Dari data & diatas dapat & disimpulkan
\end{tabular}
bahwa

media pembelajaran menggunakan Swish Max yang telah dikembangkan dikategorikan memiliki kelayakan yang amat baik dan dapat digunakan sebagai media pembelajaran mandiri khususnya pada materi momentum impuls dan tumbukan untuk siswa SMA.

\section{Kajian Produk Akhir}

Adapun kajian produk akhir dari media yang telah dikembangkan sebagai berikut:

a. Halaman depan

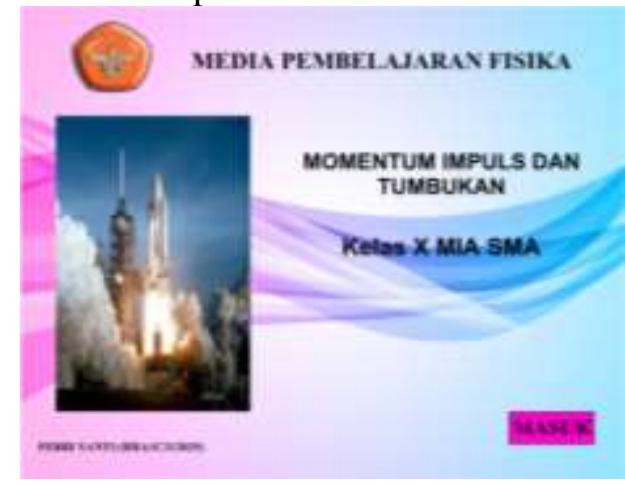


b. Halaman Menu

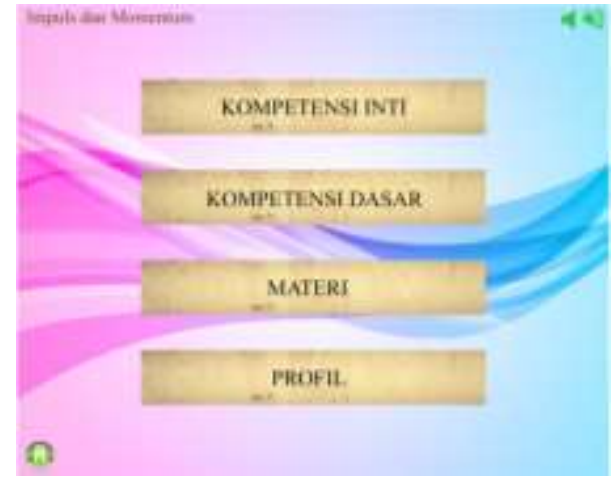

c. Halaman Kompetensi Inti

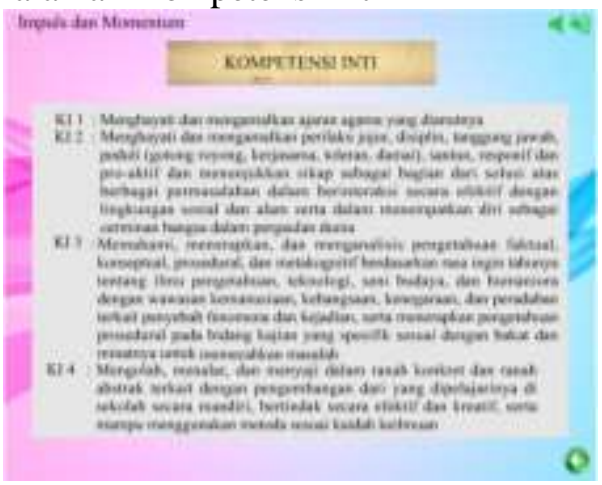

d. Halaman Kompetensi Dasar

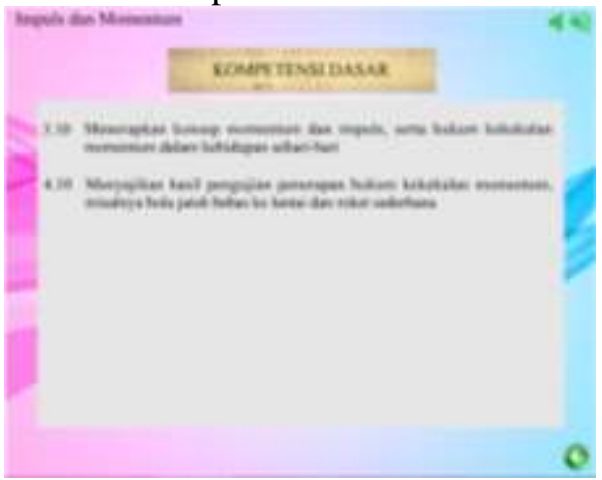

e. Halaman Materi

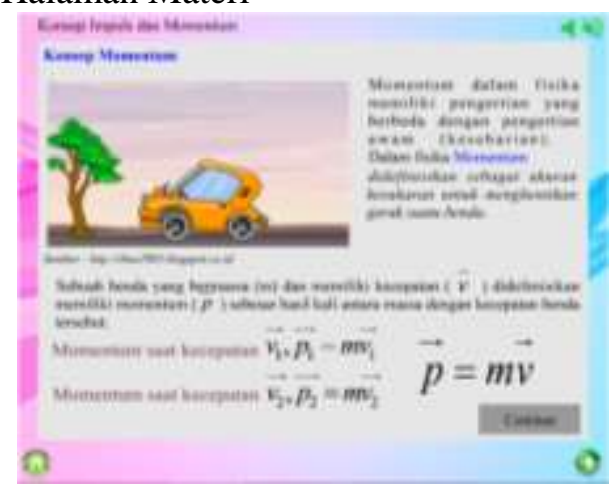

f. Halaman Contoh Soal

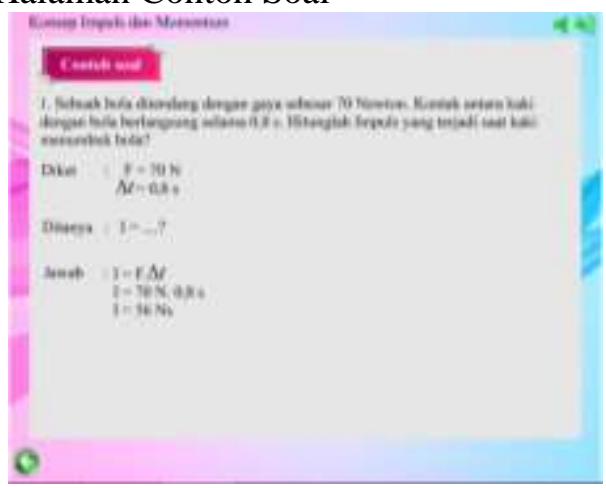

g. Halaman Evaluasi
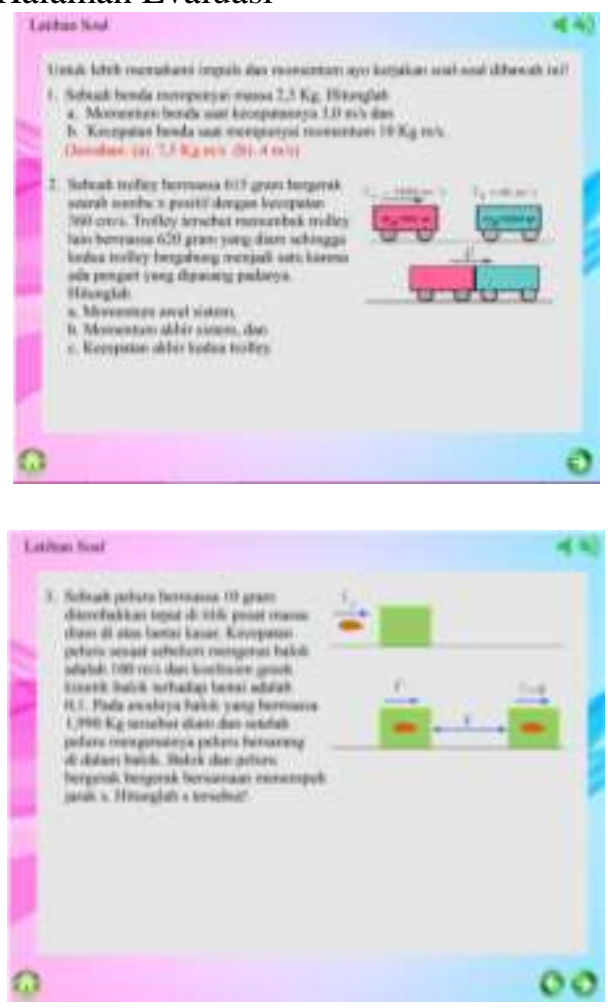

h. Halaman Profil

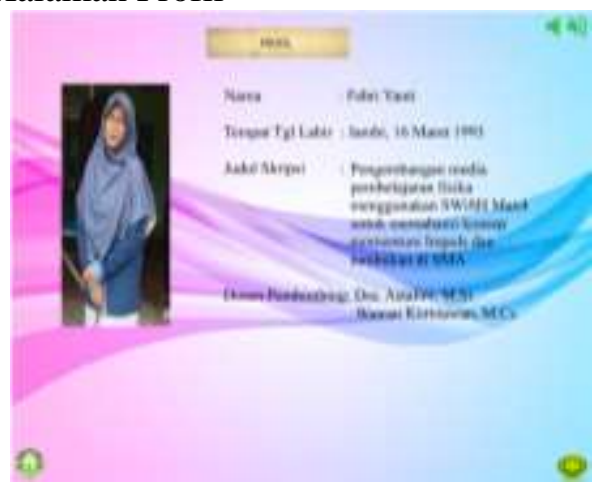

\section{Spesifikasi}

1. Format dari program: flash (swf), movie (avi) dan execute (exe) 
2. Produk dalam bentuk flash yang di dalamnya terdapat teks, gambar, video, dan animasi sehingga dapat digunakan dalam pembelajaran di sekolah ataupun dimanfaatkan oleh siswa untuk belajar mandiri dirumah.

3. Di dalam media pembelajaran ini memuat intro (pembukan), pendahuluan, isi, dan penutup serta dilengkapi dengan contoh soal dan latihan soal.

4. Media pembelajaran ini telah memenuhi kriteria kualitas media pembelajaran yang meliputi:
a. Kualitas isi dan tujuan (aspek kriteria pendidikan
b. Kualitas tampilan program
c. Kualitas teknis

2. Media pembelajaran yag mengacu pada materi pembelajaran yang berlandaskan pada silabus SMA.

3. Kegunaan : sebagai media pembelajaran pada materi momentum impuls dan tumbukan.

4. Tinjauan materi : momentum, impuls, hubungan momentum impuls, hukum kekekalan momentum, tumbukan lenting sempurna, tumbukan lenting sebagian dan tumbukan tidak lenting sama sekali.

5. Tingkat penggunaan media : Sekolah Menengah Atas kelas X.

6. Multimedia ini memerlukan komputer dengan spesifikasi minimal :

a. Menggunakan Operating windows 98 sampai dengan yang terbaru.

b. Menggunakan minimal proccecor intel pentium III $600 \mathrm{MHz}$ sampai yang terbaru.

c. Menggunakan RAM minimal $512 \mathrm{MB}$

Adapun keunggulan dari media pembelajaran menggunakan SWiSH Max4 yaitu siswa dapat memfokuskan dirinya pada materi yang akan disampaikan oleh guru melalui tampilan media yang menarik karena adanya animasi, gambar dan video. Sedangkan kelemahan dari media pembelajaran ini adalah sulitnya memasukkan simbol matematika dan materi pada media pembelajaran ini hanya momentum impuls dan tumbukan.

\section{Simpulan dan Saran \\ Simpulan}

Berdasarkan hasil pengembangan dan uji coba lapangan yang telah dilakukan maka dapat ditarik kesimpulan bahwa media pembelajaran menggunakan Swish Max4 ini dikembangkan dengan prosedur Luther yang tidak komplit yakni hanya sampai pada tahap testing (uji coba). Spesifikasi produk yaitu Format dari program: flash (swf), movie (avi) dan execute(exe). Desain slide yang dibuat dengan konsistensi warna yang menarik agar tidak terkesan terlalu bewarna. Adapum materi pada media pembelajaran adalah momentum impuls dan tumbukan. Materi disajikan secara jelas dan disertai animasi, video dan gambar.

Keunggulan dari media pembelajaran menggunakan SWiSH Max4 yaitu siswa dapat memfokuskan dirinya pada materi yang akan disampaikan oleh guru melalui tampilan media yang menarik karena adanya animasi, gambar dan video. Sedangkan kelemahan dari media pembelajaran ini adalah sulitnya memasukkan simbol matematika dan materi pada media pembelajaran ini hanya momentum impuls dan tumbukan.

Media pembelajaran menggunakan Swish Max4 ini untuk pembelajaran fisika SMA kelas X MIPA layak digunakan untuk mendukung pembelajaran siswa karena telah diuji kevalidan dan kelayakannya oleh ahli materi. Hasil validasi ahli menyatakan bahwa desain berupa background, gambar, dan video yang digunakan sudah sesuai dengan tujuan pembelajaran sehingga dapat dinyatakan valid dan layak digunakan. Serta telah dilakukan pengambilan data persepsi siswa kepada siswa kelas X MIPA 4 SMA Negeri 11 Kota Jambi. Hasil data persepsi siswa yang didapatkan skor rata-rata persepsi siswa terhadap media pembelajaran menggunakan Swish Max4 sebesar 1385,8 yang termasuk kategori amat baik. Penelitian ini menggunakan rumus alpha Cronbach untuk mencari reliabilitas. Dari perhitungan yang telah dilakukan menggunakan persamaan tersebut diperoleh nilai reliabilitas angket sebesar 0,7667 dengan kategori reliabilitas tinggi.

Saran

Saran yang dapat diberikan oleh peneliti bagi peneliti berikutnya adalah:

1. Diharapkan penelitian selanjutnya yang akan mengembangkan media 
pembelajaran menggunakan Swish Max4 disarankan untuk menguji pengaruh penggunaan media pembelajaran menggunakan Swish Max4 pada pokok bahasan momentum impuls dan tumbukan kelas X SMA ini terhadap hasil belajar siswa

2. Perlu diupayakan kegiatan penelitian lebih lanjut untuk mengetahui tingkat keefektifannya dalam pembelajaran fisika

\section{Daftar Pustaka}

Agus, Made Adnyana. (2005). Animasi Flash dengan SwisHMax Bag I. Ilmu komputer.com. 2-3.

Arikunto, S. (2015). Dasar-Dasar Evaluasi Pendidikan Jilid 2. Jakarta: Bumi Aksara

Arikunto, S., (2015). Prosedur Penelitian Suatu

Pendekatan Praktik. Jakarta: Rineka Cipta.

Binanto, Iwan. (2010). Multimedia DigitalDasar Teori dan Pengembangannya. Yogyakarta: Andi.

Direktorat Pembinaan SMA. (2010). Juknis Penyusunan Perangkat Penilaian Afektif di SMA. Jakarta: Direktorat Pembinaan SMA.

Munir. 2015. Multimedia Konsep \& Aplikasi dalam Pendidikan. Bandung: Alfabeta.

Sadiman, Arief S, 2014. Media Pendidikan. Jakarta: Raja Grafindo.

Slavin, Robert E. (2008). Psikologi Pendidikan. Jakarta: Indeks.

Sutopo, Ariesto Hadi. (2003). Multimedia Interaktif dengan Flash. Yogyakarta: Graha Ilmu.

Wahono, Romisatrio. (2012). Aspek dan kriteria pembelajaran. Diakses 01 oktober 2017 dari http://romisatriawahono.net/2006/06/2 1/aspek-dan-kriteria-penilaian-mediapembelajaran/. 